\title{
De la economía social y solidaria a la solidaridad económica: transiciones hacia un conocimiento cooperativo
}

Felipe Sáez-Riquelme*

\footnotetext{
Licenciado en Ciencias Antropológicas, Universidad de Buenos Aires. Ayudante del Seminario de Grado en la Facultad de Filosofía y Letras, Universidad de Buenos Aires.

Correo electrónico:

felipe.saez.riquelme@gmail.com
}

Recibido: 17 de enero del 2016

Aceptado: 31 de mayo del 2016

Cómo citar este artículo: Sáez-Riquelme, F. (2016). De la economía social y solidaria a la solidaridad económica: transiciones hacia un conocimiento cooperativo. Cooperativismo \& Desarrollo, 24(109), xx-xx. doi: 10.16925/ co.v24i109.1503

\section{Resumen}

Propósito: tomando la experiencia de Argentina, este artículo se propone reflexionar sobre las maneras en que hasta ahora ha sido conceptualizada la economía social y solidaria en el país. Descripción: a partir del análisis de varios textos fundacionales en este campo y sintetizando parte de mis investigaciones previas, quisiera sostener que los abordajes para el estudio de estas experiencias socioeconómicas suponen un eurocentrismo en el conocimiento, a partir de lo que he denominado metodologías de la distancia, es decir, formas de conocer que omiten las relaciones de poder y descontextualizan los saberes locales en pos de generar un criterio común de análisis general. Punto de vista: estas modalidades no solo representan un ejercicio de violencia epistémica, sino también producen silencios históricos. Conclusiones: siguiendo lo que defiende Trouillot respecto a las relaciones entre el poder y la producción de la historia, lo que hasta ahora se ha vuelto visible en este campo de saber ha obturado memorias, historias y saberes asentados en la diferencia económico/ cultural. Con miras a recuperar estas historias otras, quisiera revelar los aportes del Taller de Historia Oral Andina para la creación de metodologías de la cercanía, en una transición hacia un conocimiento de carácter cooperativo y solidario.

Palabras clave: colonialidad del poder, economía social y solidaria, metodología, solidaridad económica, taller de historia oral andina. 


\title{
From the social and solidarity economy to economic solidarity: transitions toward cooperative knowledge
}

\begin{abstract}
Purpose: Looking at the experience of Argentina, this article intends to reflect on the ways in which the country's social and solidarity economy has been conceptualized to date. Description: Based on the analysis of various foundational texts in this field and synthesis of part of my previous research, I would like to argue that the approaches to the study of these socioeconomic experiences represent a Eurocentrism in the knowledge. This is based on what I have called distance methodologies, i.e., ways of knowing that bypass power relations and decontextualize local knowledge in the interest of generating common criteria for general analysis. Viewpoint: These methods represent an exercise of epistemic violence and produce historical silences. Conclusions: Following Trouillot's contention regarding the relationships between power and history production, that which has been seen in this field of knowledge to date has closed off memories, histories, and knowledge located in economic/cultural difference. In order to recover these stories of other, I wish to share the contributions of the Andean Oral History Workshop to the creation of nearness methodologies, in a transition to knowledge characterized by cooperation and solidarity.
\end{abstract}

Keywords: coloniality of power, social and solidarity economy, methodology, economic solidarity, Andean oral history workshop

\section{Da economia social e solidária à solidariedade econômica: transições para um conhecimento cooperativo}

\section{Resumo}

Propósito: tomando a experiência da Argentina, este artigo propõe-se refletir sobre as maneiras como a economia social e solidária tem sido conceitualizada até agora no país. Descrição: a partir da análise de vários textos fundacionais nesse campo e sintetizando parte de minhas pesquisas prévias, quero sustentar que as abordagens para o estudo dessas experiências socioeconômicas supõem um eurocentrismo no conhecimento, a partir do que denominei metodologias da distância, isto é, formas de conhecer que ignoram as relações de poder e descontextualizam os saberes locais para gerar um critério comum de análise geral. Ponto de vista: essas modalidades não só representam um exercício de violência epistêmica, mas também produzem silêncios históricos. Conclusões: seguindo o que defende Trouillot com respeito às relações entre o poder e a produção da história, o que até agora se tornou visível nesse campo de saber bloqueou memórias, histórias e saberes estabelecidos na diferença econômico/cultural. A fim de recuperar essas histórias outras, quero revelar as contribuições da Oficina de História Oral Andina para a criação de metodologias da proximidade, numa transição para um conhecimento de carácter cooperativo e solidário.

Palavras-chave: colonialidade do poder, economia social e solidária, metodologia, solidariedade econômica, oficina de história oral andina. 


\section{Introducción}

En Argentina, los estudios acerca de la economía social y solidaria se han establecido durante los últimos años como un espacio de saber experto sobre la alteridad económica. Al agrupar los aportes teórico-metodológicos de la economía y la sociología, y al delimitar una gran cantidad de experiencias socioeconómicas a determinadas cualidades analíticas de interés, el campo en cuestión se ha vuelto un espacio para hablar sobre las alternativas económicas al neoliberalismo, que emergen desde el movimiento popular. Sin embargo, desde su emergencia en nuestro país como un intento por investigar las formas de organización y resistencia socioeconómica del campo popular tras la crisis del 2001 hasta ahora no han sido mayormente analizados los ejes epistémicos que guían sus conceptualizaciones y las metodologías con las cuales este campo ha creado su objeto. La ausencia de estos debates señala una falta de reflexividad en la creación de determinadas políticas públicas, que encuentran límites al emparentar su horizonte de acción con otros tipos de propuestas, también en construcción, como son las del buen vivir, las alternativas al desarrollo y el postextractivismo, entre otras.

En este sentido, en el presente artículo quisiera realizar una lectura crítica de la economía social y solidaria intentando mostrar ciertos límites en la producción de su conocimiento. Como he podido desarrollar en investigaciones previas (Saez-Riquelme, 2014; 2016), la centralidad de las nociones de economía, desarrollo y alternativa nos señala el imaginario moderno/colonial bajo el cual estas experiencias socio-económicas son entendidas. Esta vez propongo interpretar estos límites metodológicamente, haciendo una lectura de los silencios, de la relación entre estos y de la construcción de una particular memoria histórica, que deja de lado las historias locales, el conocimiento centrado en el territorio y la experiencia vital de los hombres y mujeres que llevan adelante estas prácticas de diferencia económica.

Tras una breve contextualización, en la primera parte, quisiera establecer algunas de las formas en que la economía social y solidaria define, describe y prescribe a través del uso de indicadores su objeto de estudio. Las denomino metodologías de la distancia, ejercicios que, sin involucrar una mirada crítica a las relaciones de dominación y de explotación, bajo una lógica epistémica que separa en diferentes regiones ontológicas del conocimiento (lo social, lo político, lo económico, etc.), descontextualizan los saberes locales para generar un criterio común de análisis y volver plausible la construcción y desenvolvimiento del campo en sí. En la segunda parte, quisiera sostener que este intento particular por crear un herramental teórico común no solo debe ser visto como un ejercicio de violencia epistémica (Castro-Gómez, 2000). Siguiendo los planteamientos de Trouillot (1995) respecto a las relaciones entre el poder y la producción de la historia, lo que hasta ahora se ha vuelto manifiesto, visible, a través de artículos, documentos, manuales y diccionarios, simultáneamente produce silencios al expropiar a los sujetos que participan de estas experiencias de la posibilidad de representar su propia historia. El poder del documento, para el caso estudiado, no solo vuelve inteligible a la economía social y solidaria, sino también entrega una clave de interpretación histórica. En este sentido, ¿qué pasaría si aquello que llamamos "economía social y solidaria" unicamente fuera el nombre de un tipo particular de perspectiva para volver comprensibles las formas de producción y reproducción de la vida de un momento histórico dado (la crisis del 2001 en nuestro país)? En una tercera parte quisiera argumentar que mostrar los límites epistémicos y metodológicos del campo en cuestión permite de algún modo liberar a ese objeto de una serie de tautologías que hasta ahora omiten, por una parte, las relaciones históricas de poder y, por otra, la memoria local, el conocimiento centrado en el territorio y en la experiencia vital. Con vistas a este propósito quisiera relevar los aportes metodológicos del Taller de Historia Oral Andina (thoa) para indisciplinar la economía social y solidaria. Estos aportes pueden ser de gran ayuda para la creación de metodologías de la cercanía, en pos de una transición que vaya de la economía social y solidaria hacia la solidaridad económica (Marañón, 2012).

\section{La economía social y solidaria y las metodologías de la distancia}

Surgida originalmente en la Europa del siglo xix como una tendencia de disconformidad con la economía liberal de la época y bajo el amparo del pensamiento de Owen, Saint-Simon y Fourier, la economía social se ha conformado históricamente como un conjunto muy heterogéneo de discursos y prácticas abocados a franquear el modo de producción capitalista (Singer, 2007). Si bien ha estado presente en Latinoamérica en los últimos 30 años, en Argentina ha sido reactivada desde la profundización de la crisis socioeconómica 
ocurrida en la década del noventa, alcanzando mayor visibilidad a partir de la última crisis del 2001. Desde entonces se ha transformado en una importante área de interés académico y político. Su irrupción en el debate actual ha posibilitado abrir las perspectivas de análisis de la tradicional "ciencia económica" y vislumbrar los vínculos existentes entre economía, cultura, sociedad e historia. Movimientos, intelectuales y simpatizantes de todo tipo que se adscriben a ella, han encontrado ideas con las cuales cuestionar la naturalización del neoliberalismo como modelo económico. En este sentido, el lugar que asume la economía social y solidaria para criticar al neoliberalismo $-\mathrm{y}$, también, la lógica de su crítica- debe apreciarse con base en su conformación histórica de larga duración en el continente. Los debates sobre marginalización, economía informal y pobreza al interior de los discursos y prácticas del desarrollo presentes desde la segunda mitad del siglo xx establecen una continuidad para los marcos de referencia en los cuales se ubica la otra economía ${ }^{1}$. Entonces, el surgimiento de la economía social y solidaria debe ser aprehendido al interior de las disputas por los modelos de desarrollo y este último entendido como su eje epistémico central (Sáez-Riquelme, 2014).

Siguiendo a Guerra (2002), la economía social y solidaria busca dos grandes objetivos: 1) rescatar las diversas experiencias de hacer economía en sus diferentes fases - producción, distribución, consumo y acumulación- caracterizadas por estructurarse en torno a valores solidarios, y 2) construir el herramental teórico necesario para dar cuenta de estas experiencias. Al respecto, posee dos tradiciones teóricas diferentes: una europea y otra latinoamericana (Mutuberría Lazarini, 2010; Oxoby, 2010). En ambas han sido la economía y la sociología, con sus respectivas metodologías, las disciplinas científicas dominantes para su tratamiento. La atención dada por estas disciplinas se ha dirigido hacia una serie de prácticas socioeconómicas de diversos tipos, tales como el sector voluntariado, el filantrópico, el no monetario, el no lucrativo, de interés social, el tercer sector, ong, y otras que, aunque intenten describir realidades similares, no siempre delimitan el mismo campo de actividades (Oxoby, 2010). Este

\footnotetext{
1 La noción de otra economía cumple un papel central en cómo ha sido pensada la economía social y solidaria. Este concepto está presente de manera explícita en gran parte de la producción académica referida al tema y en el corpus discursivo que este artículo trata.
}

problema conceptual, aun en curso, no ha interrumpido la proliferación de estudios, estadísticas, investigaciones y nuevas conceptualizaciones en torno al tema. Durante la última década el número de publicaciones ha crecido exponencialmente ${ }^{2}$, enmarcadas en redes académicas que articulan entre sí a comunidades, organizaciones gubernamentales y no gubernamentales, empresas de diverso tipo, voluntarios, profesionales e intelectuales, quienes suelen autoidentificarse y reconocerse entre sí como parte de este campo determinado. Un resultado de estos intercambios ha sido la creciente oferta de capacitaciones, cursos, seminarios, maestrías u otros estudios de posgrado en casi todos los países de la región. En Argentina han sido en su mayoría editoriales ligadas a universidades las que han realizado las más importantes contribuciones a la distribución, organización y compilación de los temas centrales de esta otra economía. Respecto al campo de estudios en cuestión, las formulaciones de Razeto (1984) sobre la "economía popular de la solidaridad", la propuesta de Coraggio (1992) acerca de la "economía del trabajo", la conceptualización de Singer (2004) de "economía solidaria” y la opción que ofrecen Hinkelammert y Mora (2005) de una "economía para la vida" representan un marco de referencia obligatoria en las discusiones en torno a la economía social y solidaria, especialmente en Argentina ${ }^{3}$. Tomando estos aportes y ampliándolos ${ }^{4}$ a continuación quisiera mostrar algunas de las formas en que la economía social y solidaria define, describe y prescribe a través del uso de indicadores su objeto de estudio.

2 No nos referimos sólo a publicaciones de orden académico,
sino también a manuales, guías, revistas, entrevistas, declaraciones
y manifiestos. Para una muestra general, ver: www.economiasolida-
ria.org. 3 Estas formulaciones son hegemónicas en el campo en cuestión. Existen, a su vez, perspectivas críticas respecto al tema. Véanse Presta (2007; 2009), Vargas Soler (2008) Figueira y Concha (2011), Marañón y López (2010), Marañón et. al. (2012), Saez Riquelme (2014 y 2016) entre otras.

4 Vale aclarar que el prestigio de un discurso no solo está determinado por el prestigio de su autor, sino de acuerdo al espacio institucional en el cual se inscribe (Foucault, 1979; Van Dijk, 2006). $\mathrm{Al}$ respecto, sostenemos que existen dos corpus discursivos que podrían considerarse como los más representativos de este campo de estudios para el contexto argentino y que reúnen a sus más importantes especialistas, la revista Rilees (disponible en: www.rilees.org/ otraeconomía ) y Cattani (2004). 


\section{Definición y descripción de "economía social y solidaria", prescripciones acerca de esta e indicadores}

Al revisar, consultar y analizar parte de la bibliografía referente a la economía social y solidaria, nos encontramos con una gran cantidad de documentos que abordan el tema de qué es la economía social y solidaria y que se detienen en esa pregunta. El eco de esta pregunta rebota de un texto a otro, y eso muestra que la heterogeneidad de producciones teóricas y prácticas socioeconómicas que llevan este nombre forman parte de procesos y tendencias inherentes al actual periodo del capitalismo, $y$, en tal condición, su propio carácter es "históricamente ambiguo y políticamente contradictorio" (Quijano, 2008, p. 12). Existe, entonces, una falta de consenso respecto a su definición (Guerra, 2007). Ante la imposibilidad de definir, lo que aparece en estos discursos son descripciones, es decir, caracterizaciones de la economía social y solidaria acotadas a una serie de rasgos específicos:

[La economía social y solidaria es] un modo de hacer economía, organizando de manera asociada y cooperativa la producción, distribución, circulación y consumo de bienes y servicios no en base al motivo de lucro privado sino a la resolución de las necesidades, buscando condiciones de vida de alta calidad para todos los que en ella participan, sus familiares y comunidades, en colaboración con otras comunidades para resolver las necesidades materiales a la vez que estableciendo lazos sociales fraternales y solidarios, asumiendo con responsabilidad el manejo de los recursos naturales y el respeto a las generaciones futuras, consolidando vínculos sociales armónicos y duraderos entre comunidades, sin explotación del trabajo ajeno (Coraggio, 2007, p. 14; cursivas añadidas).

[La economía social y solidaria es] un nuevo modo de hacer economía, o sea el establecimiento de una racionalidad económica especial, distinta, alternativa, que da lugar: a nuevas formas de empresa basadas en la solidaridad y el trabajo; a nuevas formas de distribución que articulan relaciones de intercambio justas con relaciones de comensalidad, cooperación, reciprocidad y mutualismo; a nuevas formas de consumo que integran las necesidades comunitarias y sociales a una matriz de necesidades fundamentales para el desarrollo integral del hombre y la sociedad; y a un nuevo modo de acumulación, centrado en los conocimientos, las capacidades de trabajo, la creatividad social, la vida comunitaria y los valores humanos, capaz de asegurar un desarrollo sustentable social y ambientalmente (Razeto, 2002, p. 2; cursivas añadidas). [La economía social y solidaria] refiere a las organizaciones de productores, consumidores, ahorristas, etc., que se distinguen por dos especificidades: (a) estimulan la solidaridad entre los miembros a través de la práctica de la autogestión y (b) practican la solidaridad hacia la población trabajadora en general, con especial énfasis en la ayuda a los más desfavorecidos (Singer, 2004, p. 199; cursivas añadidas).

Estas tres descripciones, si bien no son capaces de definir a la economía social y solidaria, mencionan rasgos de esta: el estímulo y la práctica de la solidaridad; el resurgimiento de la vida comunitaria y de los valores humanos; la emergencia de lazos sociales que valoran las necesidades humanas; la producción sin la explotación del trabajo ajeno, etc. Estas características tienden a dar relieve a la dimensión humana de una economía humana. Esta comprensión "humanista" de esta disciplina, como contraparte de lo "inhumano" del mercado, la sitúa como una caracterización negativa: la economía social y solidaria es todo lo que no es el mercado. Es un intento de definición negativa; no por la naturaleza de lo descrito, sino porque se construye en oposición a las características del mercado. Todo lo que no es el mercado, o lo que no ha podido ser, en potencia puede llegar a ser la economía social y solidaria. Esta estrategia de definición por contraste es utilizada en la definición de economía solidaria que podemos leer en el Diccionario internacional de otra economía:

La economía solidaria es un concepto ampliamente utilizado en varios continentes, con acepciones variadas que giran alrededor de la idea de solidaridad, en contraste con el individualismo utilitarista que caracteriza al comportamiento económico predominante en las sociedades de mercado (Gaiger y Laville, 2009, p. 162$)^{5}$.

Al ser una definición contenida en un diccionario y tener importancia dentro de este campo de estudios, la de Gaiger y Laville ejemplifica lo que hemos señalado: el contraste es un rasgo central en estas descripciones. Pareciera que la economía social y solidaria es una reacción a la economía de mercado, y, en tal condición, no pueda definirse de manera autónoma.

$5 \quad$ La traducción es nuestra. 
Por otra parte, en su carácter positivo, estas descripciones no son las únicas que sitúan a la economía social y solidaria como la contraparte del mercado y en pos de un ethos humanista:

Podríamos en tal sentido definir a la Economía de la Solidaridad como un modo especial y distinto de hacer economía, que por sus características propias consideramos alternativas respecto de los modos capitalista y estatista predominantes en los mercados determinados (Guerra, 2002, p. 1).

[La economía social y solidaria] crea emprendimientos colectivos, organizados a partir de los principios de la autogestión y democracia participativa en las relaciones de producción y organización del trabajo. Son principios antagónicos al capitalismo, por ello tienen una potencial crítica práctica hacia la propia sociabilidad capitalista orientada por los valores de la competición, individualismo y acumulación privada del capital a cualquier costo (Marqués, 2009, p. 2; cursivas añadidas).

La llamada economía social puede significar una pista para asumir conscientemente un programa de superación del orden capitalista. Insistimos en denominar socialista a ese programa transformador (Gambina, 2005, p. 22; cursivas añadidas).

[...] una economía puede ser solidaria sólo si y en la medida en que no es económica (Caille, 2003, p.12; cursivas añadidas).

Estas descripciones complementan a las anteriores, en la medida que hablan de la economía social y solidaria como una "alternativa". Pero más aún: son lo antagónico, son la superación, no solo del capitalismo, sino también de la economía misma. La diferencia con las anteriores, como puede verse, resulta de describir a la economía social y solidaria como una instancia transformadora del sistema en general, y no únicamente de los sujetos que realizan estas prácticas. En este sentido, a través de estas breves descripciones, queda manifiesto un debate recurrente entre las diversas perspectivas: ¿la economía social y solidaria conforma una alternativa sistémica o constituye un subsistema dentro de la actual configuración económica? ${ }^{6}$ sta pregunta es central para

6 "Más allá de las diferencias entre los diferentes abordajes, de si la economía social y solidaria conforma en sí misma una alternativa sistémica o si constituye un subsistema dentro de la actual configuración económica [...] lo que resulta importante señalar es que las diferentes perspectivas involucradas. Su importancia no es menor, ya que tanto la pregunta como las posibles respuestas "comienzan a tomar fuerza en un marco de crisis de las grandes teorías emancipatorias" (García-Guerreiro, 2010, p. 77). No obstante, la pregunta en sí misma, así como también las definiciones y descripciones de la economía social y solidaria, es acerca de una "alternativa" como una homogeneidad. La otra economía parece pretender enmarcarse en un proyecto único de otro mundo. Pese a que las descripciones de la economía social y solidaria son variadas, y las prácticas a las cuales refieren varían según las realidades sociales que enfocan, existe un vasto consenso acerca de la importancia de la creación y fortalecimiento de la economía social, "en su contribución a la democratización, a la idea de otra forma de hacer economía, más social y más humana portadora de potencial de inclusión económica y social" (Oxoby, 2010, p. 154). Es decir: lo importante no es la vasta dispersión conceptual, sino la amplia coincidencia en hacer de la economía social y solidaria otra forma de hacer economía. En otras palabras, de crear una alternativa para la otra economía. En esta búsqueda se hace explícita una de las críticas de Vargas Soler (2009) al campo en cuestión: la idea de que la economía representa un ámbito privilegiado de la existencia social y, por ende, modificándola es posible el cambio social.

Como he mencionado anteriormente, las definiciones y descripciones sobre la economía social y solidaria la plantean en oposición a la economía de mercado, resaltando el carácter humano de la primera y definiendo como su contraria a la segunda. Acorde a esta lógica, en la apertura de uno de los libros más prestigiosos que han tratado el tema, La otra economía, Cattani sostiene: "[L]a economía capitalista necesita ser superada. Bajo todos los aspectos, ella es predatoria, explotadora, deshumanizada y, ante todo, mediocre, y ya no corresponde a las potencialidades del tiempo presente" (Cattani, 2004, p. 23). A través de la economía social y solidaria, el desafío es ante todo situarse, desde ahora en adelante, "después

estas concepciones comienzan a tomar fuerza en un marco de crisis de las grandes teorías emancipatorias" (García-Guerreiro, 2010, p. 77). Lo que esta pregunta pone en juego es similar a los debates acerca de la relación entre desarrollo y los estados nacionales en el contexto latinoamericano de los sesenta y setenta, que giraron en su mayoría en torno a la oposición entre reformismo y revolución, sobretodo al interior de la izquierda latinoamericana. Algunas huellas de estas formulaciones en el campo de la economía popular pueden verse en Quijano (1998). 
del capitalismo" (Cattani, 2004, p. 28). Por lo tanto, el desarrollo de nuevas formas de hacer economía se corresponde con una lógica unilineal del tiempo. En especial, lo que se da por sentado es que, para que sea una verdadera otra economía y no solo una alternativa para pobres y excluidos, debe presentarse como una superación del sistema capitalista y debe dar pruebas de esto. Entonces, se trata tanto de un proyecto incompleto como de un proyecto superador del capitalismo. Este deber de superar al capitalismo, es afirmado cada vez que se habla sobre el horizonte de acción de la economía social y solidaria:

[...] no basta con que sean alternativas para pobres y excluidos: es menester que proporcionen logros en todos los dominios, involucren de manera responsable a amplias capas de la sociedad, que rescaten, para fines más generosos, lo que la creatividad humana pudo aplicar en la generación de productos y servicios de mejor calidad. Los intentos de volver a una época precapitalista mítica y bucólica serían pueriles. El esfuerzo debe estar orientado a recuperar socialmente aquello que el progreso técnico proporcionó en término de confort y calidad de vida (Cattani, 2004, p. 28; cursivas añadidas).

[...] el papel de los emprendimientos económicos solidarios consiste en dar pruebas tangibles de que son estructuralmente superiores a la gestión capitalista, en el desarrollo económico y en la creación de bienestar social, ya que disponen de ventajas comparativas emanadas de su forma social de producción específica (Gaiger, 2004, p. 237; cursivas añadidas).

Las pruebas tangibles de una superioridad estructural se manifiestan en las ventajas comparativas de esta forma de producción específica. Pero el papel de los emprendimientos solidarios consiste en dar esta prueba, es decir, en servir como un ejemplo tangible, real, de aquella superación. En este punto, podríamos preguntarnos: ¿estos documentos hablan de prácticas que realmente existen o de unas que deben llegar a existir? Como veremos, estas tensiones entre el ser y el deber ser deben circunscribirse a formas distantes de producción de conocimiento, aquellas que, desde modelos abstractos o tipos ideales, imaginan determinadas dinámicas sociales con anterioridad a la experiencia histórica.

Cuando Coraggio (2004) nos presenta su noción de economía del trabajo, definida como una oposición punto a punto frente a la del capital, la entiende como un nuevo tipo economía que aún no ha llegado a ser: "Aquí se plantea la posibilidad de desarrollar una economía centrada en el trabajo para satisfacer las necesidades de todos y mediada por diversas relaciones de solidaridad" (Coraggio, 2004, p. 153). Para que pueda desarrollarse, esta economía deberá estar mediada por la solidaridad. Este es uno de los indicadores, de índole cualitativo. Pero atención:

Desarrollar esa posibilidad incluye una lucha cultural, pues los comportamientos inmediatistas de los ciudadanos, en tanto consumidores, pueden contribuir a amplificar los desequilibrios que el capital descuida, y contribuir a la reproducción ampliada del capital antes que la del trabajo (Coraggio, 2004, p. 154).

Peor aún, el peligro acecha a todos, porque incluso sectores conscientes de la economía social "pueden ser llevados por la 'prueba del mercado' a internalizar formas de organización, valores y criterios de eficiencia de la empresa privada, aun cuando el lucro no sea su objetivo" (Coraggio, 2004, pp. 153-154). En este sentido, ante los peligros que se ciernen sobre el proyecto todavía incompleto de la economía social y solidaria, es necesario plantear una dirección, un horizonte hacia donde dirigir los emprendimientos:

[...] esa economía popular emergente, no reconocida por el Estado o condenada a la ilegalidad, no garantiza la sobrevivencia de todos, y se requiere una aproximación sistémica para transformar ese todo caótico en un conjunto orgánicamente vinculado de producción y reproducción, que vuelva a vincular el trabajo con la satisfacción de necesidades definidas históricamente por sociedades democráticas (Coraggio, 2004, p. 154).

Esa economía popular emergente no es aún la economía social y solidaria, porque no garantiza la supervivencia de todos, es decir, no logra superar a la economía del capital. Pero, para superarla, una aproximación sistémica, que puede entenderse como un acercamiento centralizado y holístico, puede dar forma al caos fragmentario de esa economía popular. El uso del demostrativo esa para referirse a la economía popular no es más que un modo estratégico de desmarcarse, pero no solo de un tipo de economía, sino de aquella que es la realmente existente: "[...] la economía popular realmente existente puede dar lugar a un sistema de [e]conomía del [t]rabajo, capaz de 
representar y dar fuerza efectiva a los proyectos de calidad de vida en una sociedad más igualitaria, más justa y autodeterminada" (Coraggio, 2004, p.162). En Coraggio, esta última distancia hacia la economía popular realmente existente y su posición a favor del paradigma de la economía del trabajo nos da claras señales de las tensiones existentes entre lo que es la economía social y solidaria y lo que debería ser. Esta distancia en Gaiger (2004) se traduce en la introducción de un nuevo principio. Este autor afirma que:

Al señalar los aspectos nuevos y prometedores que las experiencias de la economía solidaria están demostrando, el concepto debe ser entendido principalmente como un instrumento para la verificación de casos concretos, según las cuestiones y los ángulos de análisis que propone, al mismo tiempo que evoca un direccionamiento histórico posible, bajo el prisma de la actuación en la sociedad (Gaiger, 2004, p. 230).

En esta propuesta se halla una doble dimensión: por una parte, el concepto de economía social y solidaria como una vara que mide la realidad de estas prácticas socioeconómicas; por otra parte, al mismo tiempo que verifica, evoca una dirección posible, es decir, deberá prescribir un tipo específico de conducta económica. En esta última cita queda plasmada la ambigüedad que este campo de estudios despliega, la de intentar desprenderse del neoliberalismo como proyecto económico, pero apelar a la "ciencia de lo económico", a sus herramientas y recursos, para dar cuenta de estas experiencias socioeconómicas otras.

Esta doble dimensión que mide, pero al mismo tiempo prescribe, puede ser interpretada de la siguiente manera: el campo teórico de la economía social y solidaria tiene como horizonte de perspectiva el desarrollo de una forma económica que supere al capitalismo. Pero para afirmarse como proyecto, debe presentar ciertos indicadores, ciertos rasgos que permitan medir el carácter distintivo de estos proyectos. La base para mostrar estas pruebas tangibles sobre la otra economía reside en la construcción de indicadores para la economía social y solidaria:

La economía solidaria se diferencia de la tradicional a partir de la utilización de una perspectiva que reconoce que ni todo puede o debe ser evaluado en términos mercantiles o cuantitativos. Mientras los indicadores económicos convencionales, por lo general, tienen un carácter monetario y cuantitativo, la práctica de la economía solidaria apunta hacia la ne- cesidad de construir indicadores cualitativos capaces también de evaluar la solidez de la sociedad, su grado de confianza cohesión social, indicando situaciones límites y evidenciando umbrales, ensanchando así las posibilidades de acompañamiento de las acciones humanas (Wautiez, Bisaggio-Soares y De-Melo-Lisboa, 2004, p. 281).

La construcción de indicadores económicos cualitativos responde a una perspectiva que intenta acompañar las posibilidades de las acciones humanas. Este acompañamiento está centrado en el análisis de las relaciones sociales y no solo en las relaciones económico-mercantiles. Es así como los conceptos de cooperación, autogestión y solidaridad cobran una importancia central; en la cual este último es el rasgo distintivo de estas formas alternativas -ya que articulan en un sentido ético-moral a la cooperación y la autogestión-. Gaiger (2004) reconoce en las formulaciones de Razeto (1993) los primeros antecedentes del uso de la solidaridad como categoría económica. Lo que llamó la atención de Razeto acerca de los grupos sociales de la periferia urbana que emprendían organizaciones económicas fue que:

Algunas de esas organizaciones lograban superar la simple garantía de subsistencia y aportaban mejoras a la calidad de vida; en determinados casos aún posibilitaban márgenes de acumulación y crecimiento económico, gracias a prácticas y valores como la solidaridad, la cooperación y la autonomía (Razeto y Calcagni como se citaron en Gaiger, 2004, p. 233).

Estas prácticas de economía popular se mostraron como sorprendentes, ya que contradecían la lógica del tipo ideal de empresa capitalista. La prueba tangible de esta distinción pronto sería conceptualizada, transformada en un indicador y concebida como un factor. Siguiendo a Gaiger (2004), "la relación entre solidarismo y empresa fue subrayada en lo que sigue, cuando se menciona que la fuerza económica de esas organizaciones descansaría en el 'factor C'” (Gaiger, 2004, p.234). El resultado de la fórmula solidarismo más empresa fue el famoso "factor c", el cual puede hallarse fácilmente en la literatura especializada. Gaiger (2004) cita extensamente a Razeto para explicarnos qué es el factor c:

En el hecho de que un elemento comunitario, de acción y gestión conjunta, cooperativa y solidaria, presenta en el interior de esas unidades económicas 
efectos tangibles y concretos acerca del resultado de la operación económica. Efectos concretos y específicos en los cuales sea posible discernir una particular productividad, dada por la presencia y crecimiento del elemento comunitario señalado, análoga a la productividad que distingue y por la cual se reconocen los demás factores económicos (Razeto, como se citó en Gaiger, 2004, p. 234).

Este elemento comunitario es tangible y concreto. Es un análogo a los factores económicos con los que se rige la ciencia económica neoliberal; por supuesto, también es tangible su productividad $\mathrm{y}$, por lo tanto, sus proyecciones de crecimiento. El factor c, como elemento tangible de la sociabilidad, cumple estratégicamente con el proyecto superador de otra economía, de dar pruebas tangibles de que es posible superar la gestión capitalista. Latente esta posibilidad, "el 'factor c' significa que la formación de un grupo, asociación o comunidad, que actúa cooperativa y cordialmente, proporciona un conjunto de beneficios a cada integrante y un mejor rendimiento y eficiencia a la unidad económica como un todo" (Gaiger, 2004, p. 234). En este sentido, el factor c es un elemento deseado, ya que al determinar la racionalidad económica de la comunidad de trabajo, si es estimulado correctamente "puede ser llevado a su pleno rendimiento como trabajo asociado" (Gaiger, 2004, p. 234).

\section{La distancia y la producción de silencios en la economía social y solidaria}

Para entender de mejor forma estas tensiones entre lo que es y lo que debería ser la economía social y solidaria, y, asimismo, para comprender sus formas de aproximación a estas experiencias socioeconómicas concretas, es necesario en primera instancia reponer en estos discursos las teorías que los sustentan. Basados en una crítica a la economía liberal, puede reconocerse: 1) un uso particular de la tendencia substantivista de la teoría económica, retomando a autores como Polanyi y Mauss (Coraggio, 2007); 2) una crítica marxista heterodoxa o en su defecto, del denominado "marxismo abierto" a la noción de economía neoclásica (Marqués, 2009), y 3) una particular perspectiva ético-moral de la solidaridad, influenciada por la doctrina social de la iglesia católica (Guerra, 2002; Razeto, 2002). Estos saberes se presentan de un modo heterodoxo y discontinuo; además son la base para un tipo de cuestionamiento económico al neoliberalismo. Las ideas de reciprocidad y solidaridad, que desnaturalizan la racionalidad instrumental como inherente al comportamiento humano, son aspectos fundamentales para la economía social y solidaria, y su intención de volver visible las experiencias económico-sociales de vastos sectores populares representan un aporte sustancial para el campo en cuestión. Sin embargo, aún cuando estos aportes sean importantes para el futuro, hay otros aspectos que no han sido del todo cuestionados. Como anteriormente he propuesto (Saez-Riquelme, 2014) y como se desprende de las conceptualizaciones anteriormente analizadas, la economía social y solidaria postula tácitamente: 1) una imagen del desarrollo homogénea y unilineal, en la cual la historia se mueve de un lugar a otro (la economía social y solidaria se entiende como una superación del neoliberalismo); 2) a la economía como instancia privilegiada de la existencia social, a través de la cual todo tipo de transformación social debe darse; 3) un humanismo antropocéntrico, que, por un lado, contrasta positivamente con lo "inhumano" del mercado, pero, por otro, ignora las relaciones de dominación y explotación entre lo humano y lo no humano (MarañónPimentel, en prensa), y 4) al neoliberalismo como una teoría económica homogénea y no como un proyecto civilizatorio de vertientes heterodoxas, heredera de una matriz colonial de poder y en la que se disputan constantemente sentidos y prácticas para extender la lógica del mercado tanto sobre lo material como lo subjetivo (Puello-Socarrás, 2010). Estas cuatro ideas que subyacen al campo teórico en cuestión reflejan una falta de reflexividad respecto al imaginario moderno/colonial bajo el cual estas experiencias socioeconómicas se imaginan. De esta forma, "la economía social y solidaria se mantiene acrítica frente a la epistemología eurocéntrica, tanto de la modernidad/colonialidad como matriz de poder, como de la ciencia económica, en tanto saber experto" (Saez-Riquelme, 2014, p. 38) ${ }^{8}$.

\footnotetext{
7 Si bien existen perspectivas que toman en cuenta la relación entre lo humano y lo no humano en la economía social y solidaria, estas hasta ahora no son centrales en el campo de estudios. Esto se debe principalmente a que las modificaciones en las relaciones con lo no humano se ven como un efecto de la transformación hacia una economía más "humana", orientada hacia la reproducción de la vida. Los últimos trabajos de Coraggio $(2013 ; 2016)$ y Hinkelammert y Mora (2009) apuntan hacia esta dirección.
}

8 Marañón Pimentel (en prensa) critica otros aspectos de los enfoques teóricos de la economía social y solidaria, complementarios con los nuestros y a los cuales adscribimos. 
Las consecuencias de esta modalidad de producción de saber se ven reflejadas en sus silencios. En estos discursos están ausentes las perspectivas, imaginarios y experiencias de aquellos que participan día a día en la economía social y solidaria; este campo presupone que debe existir una división tajante entre quienes estudian a la economía social y solidaria, y quienes se estudian. Si bien es necesario el esfuerzo general por teorizar, construir conceptos y lineamientos comprensivos generales, lo que se critica son las metodologías en que estas conceptualizaciones han sido construidas. Lo que en este trabajo he denominado como metodologías de la distancia forma parte de las modalidades eurocéntricas del conocer y del representar, que reproducen la separación entre sujeto y objeto. En este sentido, estas estrategias metodológicas son particularmente deudoras del empirismo abstracto, asentado en las metodologías dominantes y hegemónicas de la economía y de la sociología, creadoras de sujetos de saber hipotéticos, abstractos, quienes participan en dicha creación como ejemplos o apéndices de la teoría. Esta modalidad de construcción de conocimiento, que CastroGómez (2000) denominó "violencia epistémica", al negar las perspectivas históricas y las experiencias vitales de los sujetos de quienes se habla, en el mismo movimiento en que producen teoría, consiguen apropiarse de la intersubjetividad de aquellos que representan ${ }^{9}$. Esta idea, no obstante, encuentra un complemento con esta otra: representar a lo otro sin la perspectiva de que ese otro significa producir un silencio activo, obturar la memoria de aquel otro. Con el paso del tiempo este silencio incide en la creación de una memoria histórica sesgada.

9 Para el caso estudiado, en el apartado anterior hemos visto que la economía social y solidaria establece prescripciones de lo que debería ser sin considerar el punto de vista de los actores involucrados. En mi propia experiencia de trabajo de campo (Saez-Riquelme, 2014; 2016) he sido testigo de cómo mis interlocutores reproducen definiciones respecto a lo que ellos para la teoría hacen (conceptos como reciprocidad, comercio justo y "alternativa") sin ellos haber decidido ni problematizado estas ideas, lo que refleja una tajante división entre quienes producen teoría y quienes se, a través de la teoría, representan. Los silencios de estas formas de representación, como quisiera mostrar, inciden en la creación de un imaginario común y en el establecimiento de una particular perspectiva histórica.
En este punto quisiera seguir los planteamientos de Trouillot (1995) respecto a las relaciones entre el poder y la producción de la historia. Analizando el caso de la Revolución Haitiana, este autor argumenta que esta ingresó a la historia con la característica peculiar de haber sido inconcebible incluso en el momento mismo en el que ocurría. La mayoría de quienes fueron contemporáneos a los acontecimientos revolucionarios fueron incapaces de comprenderla en sus propios términos; se explicaban lo que sucedía siguiendo las categorías de un orden ontológico específico, es decir, de una visión de mundo moderno y colonial, en la cual se presupone que los esclavos negros no son capaces de proclamar la libertad y autogobernarse. Para el autor esta inverisimilitud convirtió para la posteridad a la Revolución haitiana en un no evento, ya que si algunos eventos no se pueden aceptar en el momento en que suceden, “¿cómo se pueden entender más tarde? En otras palabras, ¿pueden las narrativas históricas dar cuenta de tramas que son inverosímiles para el mundo dentro del cuál ocurren? ¿Cómo escribir una historia de lo imposible?" $\left(\right.$ Trouillot, 1995, p. 73) ${ }^{10}$. Lo impensable, que al interior de una narrativa histórica se vuelve en un no evento, habla más de los marcos conceptuales que de los eventos en sí:

La Revolución haitiana si transformó las premisas ontológicas y políticas de la mayoría de los escritores radicales de la Ilustración. Pero los eventos que estremecieron a Saint Domingue de 1791 a 1804 constituyeron un escenario para el cual ni la más extrema izquierda política de Francia o Inglaterra tenía un marco conceptual de referencia. [...] Lo impensable es aquello que no se puede concebir dentro del rango de alternativas posibles; es lo que pervierte todas las respuestas porque desafía los términos bajo los cuáles se formulan las preguntas. Por esta razón, la Revolución haitiana fue inconcebible en su tiempo: desafió el horizonte mismo de sentido que le servía a oponentes y defensores para pensar el colonialismo, la raza y la esclavitud en las Américas (Trouillot, 1995, p. 83). $<$ Fin de cita $>$

Pero no solo marcos conceptuales, sino también las formas que asumen determinados métodos al interior de aquellos. En este sentido, el poder del documento escrito, al mismo tiempo que vuelve inteligible un fenómeno -intenta definir o describir

10 La traducción es propia. 
lo que sucede-, desde cierta distancia temporal, se vuelve una posible clave de interpretación histórica de ese fenómeno, volviéndose a posteriori parte constituyente de una narrativa específica. Para el caso de la economía social y solidaria, lo que hasta ahora se ha puesto de manifiesto a través de documentos, manuales y diccionarios, anclados en metodologías de la distancia, establecen una narrativa singular de un evento histórico específico. En este sentido, cabe preguntarse qué pasaría si aquello que llamamos “economía social y solidaria” solo fuera el nombre de un tipo particular de perspectiva para volver inteligibles ciertas formas de producción y reproducción de la vida en un momento histórico dado (la crisis del 2001 en nuestro país). Esta perspectiva, como antes hemos señalado, hereda los debates sobre marginalidad y economía informal, en la cual aún se asume como actor social principal al "pobre" y de su problema, la "pobreza", como su nodo central, entendida esta como la falta de capacidad para producir o para realizar su potencial productivo (Sen, 1992). Esta perspectiva hereda los debates de las últimas décadas en la región, ceñidos fundamentalmente en el empirismo como postura dominante para la indagación sobre la existencia social y el pragmatismo en la acción social (Quijano, 1998) ${ }^{11}$. Esta postura, en definitiva, entronca al saber general de la economía en una serie de experiencias socioeconómicas dispersas, discontinuas y fundamentalmente, arraigadas al territorio y a la diferencia. ¿Deberíamos suponer entonces que

11 "Hoy, de nuevo, la postura dominante en la indagación sobre la existencia social es el empirismo. y en la acción social, el pragmatismo. El empirismo es una resistencia a la totalización y a la historización de los fenómenos sociales, a dar cuenta no sólo de las relaciones inmediatas, sino también de los campos de relaciones de tales fenómenos en cada contexto concreto y sobre todo en el largo plazo. Desde ese punto de vista, el poder es un dato, no una cuestión. El pragmatismo consiste, en lo fundamental, en la exclusión de toda pregunta y de todo debate sobre los fines y las consecuencias históricas de la acción social. La perspectiva resultante de esa hibridación del empirismo con el pragmatismo no admite que pueda tener lugar, ni sentido, ningún conflicto en el cual estuvieran o pudieran estar en cuestión el carácter y los fundamentos históricos del poder vigente. Por lo mismo, todo conflicto social aparece apenas como una transitoria y circunstancial anomalía del consenso" (Quijano, 1998, p. 24). la economía social y solidaria es una perspectiva de aproximación parcial a la diferencia económica y cultural, que con sus formas de producción de conocimiento volvió pensable toda una serie experiencias socioeconómicas alternativas?

\section{Volver indisciplinar a la economía social y solidaria: Pasos hacia la solidaridad económica}

Quizás la economía social y solidaria sea la historia de un nombre, que por circular de boca en boca -o de texto en texto- logró hacer olvidar que las resistencias a la colonialidad del poder desde la producción y reproducción de la vida han tenido múltiples nombres. Desnaturalizar la economía social y solidaria significa mostrar sus límites para de algún modo superarlos con la creación de formas de conocimiento descolonizadoras. Esto se enmarca en lo que Marañón-Pimentel y López (2014) han denominado "solidaridad económica". Si bien los autores incluyen los aportes teóricos de la economía social y solidaria al interior de la solidaridad económica, entienden a esta última como parte decisiva de un proyecto alternativo societal: del buen vivir y de la decolonialidad del poder. Esto modifica críticamente las formas en que el campo en cuestión podría construirse, ya que la decolonialidad, al proponer una ruptura con el eurocentrismo como forma de conocimiento, implica, por un lado, volver visibles las relaciones de poder -de dominación, de explotación y de conflicto- que tiñen todas las dimensiones de la vida y, por el otro, resaltar las prácticas sociales emergentes que propugnan formas otras de relacionarse, que apuntan a la negación de las relaciones de dominación y de explotación propias del patrón de poder moderno y colonial. En este sentido, desde la solidaridad económica, las experiencias de diferencia económico-cultural deben estudiarse:

a) desde la totalidad social y no desde el reduccionismo económico, b) tratando de teorizar sobre las mismas como parte de un proyecto societal y no limitarse a describirlas (empirismo) [sic], y c) considerando el contexto histórico-estructural en que surgen, esto es, teniendo en cuenta las recientes tendencias del patrón de poder moderno/colonial capitalista (Marañón-Pimentel y López, 2014, p. 168).

Desde la solidaridad económica, la producción de conocimiento significa estudiar dichas 
experiencias incorporando las relaciones de poder $y$, a su vez, asumiendo una postura ética comprometida con los sectores populares dominados y explotados, al reconocer y legitimar sus prácticas, sus conocimientos, sus visiones de mundo y, por tanto, proponer formas alternativas de organización social. En este sentido, las prácticas de producción de conocimiento de la solidaridad económica buscan indisciplinar los saberes:

Indisciplinar significa desatar las fronteras de las ciencias sociales que cercan la producción y distribución del conocimiento, y las "regiones ontológicas" de lo social, lo político y económico. Implica el reconocimiento de otras formas de conocimiento, particularmente los conocimientos locales producidos desde la diferencia colonial, y los entrecruces y flujos dialógicos que pueden ocurrir entre ellos y los conocimientos disciplinares. Además, propone romper con las tendencias modernistas de las ciencias sociales que dividen y distancian el sujeto y el objeto de conocimiento para, así, replantear la relación dialógica entre sujeto y estructura (Castro-Gómez, Schiwy y Walsh, 2002, pp. 13-14).

Indisciplinar implica producir flujos dialógicos, en los cuales se reinventan los saberes en una interculturalidad epistémica. Indisciplinar, así mismo, implica repensar la forma como los científicos sociales generamos conocimiento. En este sentido, tradicionalmente el problema de la distancia y la cercanía en la investigación social puede ser visualizado según dos situaciones hipotéticas: por una parte, desde la cercanía, el investigador tendría que investigar "sin teoría" para reconocer la dimensión "nativa" del conocimiento. El problema que surge aquí es el siguiente: ¿es posible hacer una investigación sin un marco teórico previo? Por otro lado, desde la distancia, el investigador debería investigar con un fuerte marco teórico previo. La pregunta que surge aquí es ¿qué se pierde y qué se gana si hacemos que la realidad se adecue a la teoría?; ¿es deseable? Siguiendo los planteamientos de Suárez-Krabbe (2011), la distancia y la cercanía, como han sido planteadas en estos ejemplos hipotéticos, aún giran en torno a las preocupaciones sobre la integridad teórica y disciplinaria del investigador. Es decir, siguen entrampadas en relación con la validez y la evidencia de determinado campo disciplinario. De acuerdo con esta última idea, "indisciplinar" significa también descentrar al investigador de su posición como protector de una disciplina, en pos de volverlo un aprendiz de las teorías "nativas", de las experiencias históricas y de las perspectivas locales y que, a través del diálogo y la discusión, emerjan nuevas formas de democratizar el conocimiento. Las metodologías de la cercanía, entonces, comienzan por un principio ético de descolonización ${ }^{12}$.

\section{Hacia metodologías de la cercanía: algunos apuntes sobre el thoa}

Es en esta dirección que la cercanía debe entenderse como parte de la in-disciplina. No se trata simplemente de estar cerca; es usar los principios de la reciprocidad y la solidaridad también en el ámbito de la producción de conocimiento, en la cual la flexibilidad metodológica, la creatividad y la experiencia colectiva se vuelven centrales para la descolonización. En este sentido, es importante rescatar los aportes del posdesarrollo (Escobar, 1999) particularmente en la forma en que su autor imagina nuevas formas de investigación, al proponer modificar la relación entre el investigador y sus interlocutores en una mediación de índole político-epistémica, en pos de debatir y cuestionar al desarrollo ${ }^{13}$. En una dirección similar, los aportes del thoa también incluyen un carácter cooperativo en la producción de saberes y pueden constituir un enriquecedor ejemplo para las propuestas de la solidaridad económica. Se trata de un grupo de trabajo indígena que reúne investigadores aymara-qhichwas y urus con el objetivo de investigar, difundir y revitalizar la cultura, la historia y la identidad de los pueblos indígenas de los Andes. Desde principios de los ochenta comenzaron a indagar sobre el papel de los indígenas en las luchas populares. Sin embargo, en los archivos, las hemerotecas y las bibliotecas apenas existían referencias o bibliografía que permitiera reconstruir la historia desde el punto de vista de los excluidos. No tuvieron otra opción que utilizar métodos alternativos. Empezaron por entrevistar a los mayores de las comunidades, quienes habían protagonizado las luchas de los pueblos indígenas o las habían oído transmitidas de generación en generación. Estos encuentros servían como espacios de encuentro y de transmisión de experiencias

\footnotetext{
12 Las metodologías de la cercanía están inspiradas en las interesantes reflexiones de Suárez-Krabbe (2011) respecto a la proximidad metodológica para el campo de la antropología.
}

13 Para ver de qué forma el autor lleva a una práctica de investigación esta propuesta, se recomienda Escobar (2010). 
de lucha para las nuevas generaciones. Es así como tiempo después el thoa influiría en la creación una de las más influyentes organizaciones indígenas de la actualidad, el Consejo Nacional de Ayllus y Markas del Qullasusyu (Conamaq).

La historia oral de las luchas de las comunidades desde principios de siglo pasado contra el régimen de las haciendas marca un antecedente en la historiografía boliviana, no solo por revelar una historia silenciada, sino por inaugurar un espacio de crítica, tanto hacia el orden colonial como hacia la concepción occidental de la historia, que sitúa lo histórico tan sólo a partir de la aparición de la escritura. Para Rivera-Cusicanqui (1987), la práctica historiográfica indígena permite descubrir estratos muy profundos de la memoria colectiva, de otro modo imposibles de capturar. Otro aspecto vinculado se refiere a la conexión entre historia oral e historia "estructural". La coexistencia de múltiples historias no configura un universo desorganizado de historias locales inconexas, sino que el eje colonial -la colonialidad del poder- organiza a todas ellas en una cadena de gradaciones y eslabonamientos de unos grupos sobre los otros. En este sentido, "la cuestión colonial apunta a fenómenos estructurales muy profundos y ubicuos, que van desde los comportamientos cotidianos y esferas de 'micropoder', hasta la estructura y organización del poder estatal y político de la sociedad global" (Rivera-Cusicanqui, 1987, p. 60).

En cuanto a metodología de la cercanía, para Mignolo (2002), esta vertiente de la historia oral permite producir conocimiento "crítico", y este conocimiento y comprensión "crítico" es lo que le falta a la cientificidad de las ciencias sociales, al reordenar la relación sujeto de conocimiento y objeto para conocer o comprender. Pero más aún "[...] no es sólo una nueva 'fuente' para la historiografía. Es ella misma producción de conocimiento" (Mignolo, 2002, p. 7):

La historia oral en este contexto es, por eso, mucho más que una metodología "participativa" o de "acción” es un ejercicio colectivo de desalienación, tanto para el investigador como para su interlocutor. $\mathrm{Si}$ en este proceso se conjugan esfuerzos de interacción consciente entre distintos sectores, y si la base del ejercicio es el mutuo reconocimiento y la honestidad en cuanto al lugar que se ocupa en la "cadena colonial", los resultados serán tanto más ricos [...]. Por ello, al recuperar el estatuto cognoscitivo de la experiencia humana, el proceso de sistematización asume la forma de una síntesis dialéctica entre dos (o más) polos activos de reflexión y conceptualización, ya no entre un "ego cognoscente" y un "otro pasivo", sino entre dos sujetos que reflexionan juntos sobre su experiencia y sobre la visión que cada uno tiene del otro (Rivera-Cusicanqui, 1987, p. 61).

En este sentido, la generación de narrativas autobiográficas en busca de lo significativo de los acontecimientos incentiva a los sujetos a participar comprometidamente con su entorno social. Esta experiencia investigativa busca que las relaciones de asimetría social y cultural en el contexto de las situaciones coloniales se vuelva simétrica en el proceso tanto de investigación como de creación. Un elemento crucial de este postulado de simetría será también la disponibilidad del investigador a sujetarse al control social de la colectividad investigada: este control se refiere no solo al destino que tendrá el producto final de la investigación, sino a compartir los avatares de todo el proceso, desde la selección de temas, el diseño de las entrevistas, el sistema de trabajo, la devolución sistemática de transcripciones y las finalidades o usos de los materiales resultantes. En definitiva, a que los saberes producidos en estas relaciones sean resultado de la cercanía.

\section{Consideraciones Finales: hacia un conocimiento de carácter cooperativo y solidario}

[...] los explotados y dominados sufren la dificultad extrema, la impotencia a veces, que los derrotados tienen bajo una constante represión (el desempleo, la fragmentación estructural, la dispersión organizacional, la violencia) para expresar sus demandas en sus propios términos, desde sus propias perspectivas. Y tienen, en consecuencia, que admitir o entregar al silencio, el que sus demandas sean canalizadas en discursos compensatorios de la nueva subalternidad.

Quijano, A.

En un escenario hipotético, en cuarenta o cincuenta años más, ¿¿de qué se hablará cuando se hable de economía social y solidaria? ¿Qué historias, qué luchas serán recordadas? ¿Bajo qué perspectivas de conocimiento las recordaremos? ¿A qué silencios habremos de poner atención? Aún faltando mucho por hacer, en este trabajo he intentado mostrar ciertos límites del estado actual de la economía social y solidaria para comprender las luchas populares que se insertan en 
las diversas y heterogéneas prácticas de diferencia económica-cultural. Para sortear estos obstáculos epistemológicos, indisciplinar el campo teórico en cuestión consiste en abrir el diálogo hacia la construcción de memorias históricas diferentes, que no representen únicamente una respuesta reactiva y dependiente del mercado, sino configuren un espacio abierto a la reimaginación social, con vista a proyectos de transición más amplios, como el buen vivir y la decolonialidad. Lo que aquí se disputa no es menor: se trata de la construcción de una intersubjetividad común, que permita reconstruir las perspectivas e imaginarios de estas experiencias socioeconómicas desde el interior de estas experiencias y en diálogo con otras, no impuestas desde afuera, desde el saber experto. Las formas de conocimiento desde la proximidad, es decir, aquellas que tienden un puente político-epistémico, tal vez no permitan suspender cierta inherente sospecha respecto a la cercanía que la academia tradicional aún mantiene, pero si a través de ellas podemos establecer relaciones sociales ancladas a una ética de la descolonización. En este sentido, la proximidad que la historia oral andina nos incita a establecer como relación, ubica al investigador frente al compromiso de volver consciente las prácticas académicas de sus entornos, a través de una colaboración múltiple y enriquecedora. Así como la cooperación y la reciprocidad están presentes en los grupos que conforman la solidaridad económica, es necesario que los intelectuales nos volvamos aprendices y vayamos en sintonía con estas prácticas en nuestro propio quehacer. Dejarse guiar por la reciprocidad y solidaridad en la acción social es retomar un compromiso con la búsqueda de horizontes alternativos al actual patrón de poder.

\section{Referencias}

Castro-Gómez, S., Schiwy, F. y Walsh, C. (2002). Indisciplinar las ciencias sociales. Geopolíticas del conocimiento y colonialidad del poder. Perspectivas desde lo andino. Quito: Universidad Andina Simón Bolívar/ Abya-Yala.

Castro-Gómez, S. (2000). Ciencias sociales, violencia epistémica y el problema de la invención del otro. En E. Lander (Comp.), La colonialidad del saber: eurocentrismo y ciencias sociales. Perspectivas latinoamericanas (pp. 145-161). Buenos Aires: Clacso.
Cattani, A. D. (2004). La otra economía: conceptos esenciales. En A. D. Cattani (Comp.), La otra economía (pp. 23-30). Buenos Aires: Altamira.

Coraggio, J. L. (1992). La economía social como vía para otro desarrollo social. Recuperado de http://www.urbared.ungs.edu.ar

Coraggio, J. L. (2004). Economía del trabajo. En A. D. Cattani (Comp.), La otra economía (pp. 151-163). Buenos Aires: Altamira.

Coraggio, J. L. (2007). Economía social, acción pública y política: hay vida después del neoliberalismo. Buenos Aires: Ciccus

Coraggio, J. L. (2013). La economía social y solidaria: hacia la búsqueda de posibles convergencias con el Vivir Bien. En I. Farah y V. Tejerina (Comp.), Vivir bien: infancia, género y economía. Entre la teoría y la práctica (pp. 215-255). La Paz: cides-umsa.

Coraggio, J. L. (2016). Algunas convergencias prometedoras. En J. L. Coraggio (Comp.), Economía Social y Solidaria en movimiento (pp. 201-209). Buenos Aires: Universidad Nacional de General Sarmiento.

Escobar, A. (1999). El final del salvaje. Naturaleza, cultura y política en la antropología contemporánea. Bogotá: ican.

Escobar, A. (2010). Territorios de la diferencia: lugar, movimientos, vida, redes. Popayán, Colombia: Envión.

Figueira, P. y Concha, P. (2011). Comercio justo, otra cara del desarrollo. Gazeta de Antropología, 27(1), (pp.0118).

Foucault, M. (1979). Arqueología del saber. México: Siglo xxi.

Gaiger, L. I. (2004) Emprendimientos economicos solidarios. En A. D. Cattani (Comp.), La otra economía (pp. 229-241). Buenos Aires, Altamira.

Gaiger, L. I. y Laville, J. L. (2009). Economia Solidária. En A. Cattani, L. I. Gaiger, J. L. Laville y P. Hespanha (Comp.) Dicionário Internacional da Outra Economia (pp. 162-168). Sao Paulo: Edicoes Almedina.

García-Guerreiro, L. (2010). Espacios de articulación, redes autogestivas e intercambios alternativos en la ciudad de Buenos Aires. Otra economía. Revista Latinoamericana de Economía Social y Solidaria, 4(6), 68-82.

Guerra, P. (2007). ¿Cómo denominar a las experiencias económicas solidarias basadas en el trabajo? Diálogo entre académicos latinoamericanos acerca de la polémica conceptual. Otra economía. Revista Latinoamericana de Economía Social y Solidaria, 1(1), 21-27. 
Guerra, P. (2002). Economía de la solidaridad. Una introducción a sus diversas manifestaciones teóricas. Recuperado de www.trueque-marysierras.org.ar/biblioteca2.htm

Hinkelammert, F. y Mora, H. (2005). Hacia una economía para la vida. San José: dei.

Hinkelammert, F. y Mora, H. (2009). Por una economía orientada hacia la reproducción de la vida. Íconos. Revista de Ciencias Sociales, 33, 39-49.

Marañón, B. (Comp.). (2012). Solidaridad económica y potencialidades de transformación en América Latina. Una perspectiva descolonial. Buenos Aires: Clacso.

Marañón-Pimentel, B. (en prensa). Notas sobre la solidaridad económica y la descolonialidad del poder. En B. Marañón (Comp.), Políticas para la solidaridad económica y el buen vivir en México. México: iiec- unam.

Marañón, B. y López D. (2014). Solidaridad económica, buen vivir y (des)colonialidad del poder. Sociedad y Discurso, 25, 153-178.

Marañón, B y López, D. (2010). Economía solidaria y sociedad alternativa en América Latina. Hacia una agenda de investigación desde la descolonialidad. Alternativ@s, 67, (01-11)

Marqués, P. (2009). La economía solidaria como nuevo movimiento social contemporáneo. Recuperado de www. economiasolidaria.org

Mignolo, W. (2002). El potencial epistemológico de la historia oral: algunas contribuciones de Silvia Rivera Cusicanqui. En D. Mato (Comp.), Estudios y otras prácticas intelectuales latinoamericanas en cultura y poder ( $\mathrm{pp}$. 01-16). Caracas: Clacso.

Mutuberría-Lazarini, V. (2010). El campo de la economía social en debate. En A. García (Coord.), Repensando la economía social (pp. 11-28). Buenos Aires: Centro Cultural de la Cooperación Floreal Gorini.

Oxoby, P. (2010). Una aproximación a las divergencias e implicaciones de los distintos abordajes a la economía social: países centrales europeos y América Latina. Otra Economía. Revista Latinoamericana de Economía Social y Solidaria, 4(6), 153-166.

Presta, S. R. (2007). La categoría de don en el marco de la economía social y solidaria. Cuadernos de Antropología Social, 26, (165-182).

Presta, S. R. (2009). Paradojas de la economía social y solidaria en el marco de las transformaciones en los procesos de acumulación de capital (tesis de doctorado). Universidad de Buenos Aires, Buenos Aires.
Puello-Socarrás, J. (2010). Del homo economicus al homo redemptori: emprendimiento y Nuevo Neo-liberalismo. Otra Economía, 4(6), (181-206).

Quijano, A. (1998). La economía popular y sus caminos en América Latina. Lima: Mosca Azul Editores.

Quijano, A. (2008). Solidaridad y capitalismo colonial / moderno. Otra Economía, 2(2), 12-16.

Quijano-Valencia, O. (2012). EcoSImías. Visiones y prácticas de diferencia económico cultural en contextos de multiplicidad. Popayán: Universidad del Cauca.

Razeto, L. (1984). Economía de solidaridad y mercado democrático. Santiago de Chile: Programa de Economía del Trabajo.

Razeto, L. (1993). Los caminos de la economía de solidaridad. Santiago de Chile: Vivarium.

Razeto, L. (2002). Ponencia presentada en el II Foro Social Mundial de Porto Alegre. En el Seminario sobre la Economía de Solidaridad. Recuperado de http://www. luisrazeto.net/content/econom\%C3\%ADa-de-solidaridad-y-profundizaci\%C3\%B3n-de-la-democracia-para-una-nueva-civilizaci\%C3\%B3n

Rivera-Cusicanqui, S. (1987). El potencial epistemológico y teórico de la historia oral: de la lógica instrumental a la descolonización de la historia. Revista Temas Sociales, 11, 49-64.

Saez-Riquelme, F. (2014). Relaciones de poder, sujetos y conceptualizaciones en torno a la Economía Social y Solidaria en Argentina (2001-2011). El caso de una cooperativa de vivienda, crédito y consumo (Tesis de Licenciatura). Universidad de Buenos Aires, Buenos Aires.

Saez-Riquelme, F. (en prensa). ¿El regreso del buen salvaje? Alteridad y alternativa en el campo teórico de la economía social y solidaria. Revista Kula, 13.

Sen, A. (1992). Sobre conceptos y medidas de pobreza. Revista Comercio Exterior, 42 (4), (01-17).

Singer, P. (2007). Economía solidaria. Un modo de producción y distribución. En J. L. Coraggio (Comp.), La Economía Social desde la Periferia: contribuciones latinoamericanas. Buenos Aires: ungs-Altamira Ed.

Singer, P. (2004). Economía solidaria. En A. D. Cattani (Comp.), La otra economía (pp. 199-212). Buenos Aires: Altamira.

Suárez-Krabbe, J. (2011). En la realidad. Hacia metodologías de investigación descoloniales. Tabula Rasa, 14, 183-204. 
Trouillot, M. R. (1995). Silencing the Past: Power and the Production of History. Boston: Beacon Press.

Vargas-Soler, J. (2008). Consideraciones en torno a las propuestas de constitución y desarrollo de otra economía en América Latina. Otra Economía, 2(3), 93-111.

Van Dijk, T. (2006). Ideología. Una aproximación multidisciplinaria. Sevilla: Gedisa.

Wautiez, B. S. y De Melo Lisboa (2004). Indicadores de economía solidaria. En A. D. Cattani (Comp.), La otra economía (pp. 281-291). Buenos Aires: Altamira. 